\title{
Xylitol, a Promising Allied for Oral Heath
}

\author{
Edmir Geraldo de Siqueira Fraga', Fernanda Maria Teófilo Campos², Manoel Patrick da Silva Cavalcante, Luiz Filipe Barbosa Martins³, \\ Edilson Martins Rodrigues Neto ${ }^{3,4, *}$, Marcelo Jenné Mimica ${ }^{5}$ \\ 'Department of Health Sciences, Division of Microbiology, Santa Casa de São Paulo School of Medical Sciences São Paulo, SP, BRAZIL. \\ ${ }^{2}$ Health Multidisciplinary Residence Program, Public Health School from Ceara State, Fortaleza, CE, BRAZIL. \\ ${ }^{3}$ Catholic University Center of Quixada, Quixadá, CE, BRAZIL. \\ ${ }^{4}$ Department of Pharmacy, Dentistry and Nursing College, Federal University of Ceara, Fortaleza, CE, BRAZIL. \\ 5Department of Paediatrics, Santa Casa de São Paulo School of Medical Sciences, São Paulo, BRAZIL.
}

\begin{abstract}
This work aimed to carry out a literature review correlating the use of xylitol with the prevention of dental caries, which is a chronic and multifactorial disease, caused by organic acids originated from the fermentation of dietary carbohydrates (dependent sucrose) by bacteria and, when associated with a limited ability to correct oral $\mathrm{pH}$, lead to tooth decalcification, a process known as demineralization. The cariogenic potential of the oral microbiota is genetically determined and is accentuated by the availability of sucrose. Under these conditions, the metabolic pathways favor the reduction of $\mathrm{pH}$, demineralization of the dental substrate and the synthesis of extracellular polysaccharides that act as an energy supply and adhesive strategy. Xylitol is an alcoholic sugar that hardly undergoes fermentation by oral bacteria. Therefore, it has been recommended as a substitute for sugar, especially when food is eaten between meals, helping to prevent tooth decay. The antimicrobial activity of xylitol occurs when the compound is incorporated into the bacterial cell, through the phosphorylation process in the glycolytic
\end{abstract}

pathway of the bacterium, forming xylitol-5-phosphate, that is not metabolized by any enzyme, characterizing it as an intermediate compound. Xylitol is a safe nutrient for human use, and several studies have analyzed the influence of xylitol in dental caries prevention. However, there is a need for more robust clinical trials for the evaluation of the effectiveness of xylitol under ideal conditions propitious to its use. Key words: Dental caries, Streptococcus mutans, Xylitol.

\section{Correspondence}

Dr. Edilson Martins Rodrigues Neto,

Department of Pharmacy, Dentistry and Nursing College, Federal University of Ceara, Fortaleza, CE, BRAZIL.

Phone: +5585 3366-0000

Email: edilsonmrneto@hotmail.com

DOI: 10.5530/jyp.2020.12.60

\section{INTRODUCTION}

Oral health has been recognized, over the years, as a fundamental part of general health, not only being the absence of physical disease, but also involving social, biological, psychological and spiritual aspects. ${ }^{1}$

Dental caries are a symbiosis, sugar dependent, of multifactorial etiology, defined as the demineralization process of the dental matrix in the enamel and / or dentine induced by acid. It represents the most important and prevalent oral health problem in Brazil, being considered a public health problem and described as a social disease. Its prevalence is determined by biological, dietary, behavioral and socio-economic factors, as well as factors of access to consumer goods and health services. ${ }^{1-3}$ Despite the programs and projects carried out in the oral health promotion area, as the National Oral Health Policy, oral manifestations such as dental caries, periodontal disease and oral cancer can be a risk factor for numerous systemic diseases, bringing an important burden in morbidity and mortality that affects a large portion of the population. ${ }^{1,4}$

Dental caries are modulated by multiple factors, including the presence of acidogenic bacteria, which produce dental structure demineralization, affecting a large number of individuals in the world, specially the pediatric population. ${ }^{5}$

In Brazil, caries disease is verified through the DMFT index, which means the average number of permanent decayed, lost and filled teeth, at 12 years of age, in a given geographical space, in the considered year. This index estimates the present and past experience of the dental caries attack to permanent dentition. The age of 12 years is adopted internationally as a basic parameter for the indicator use. The index values correspond to the following degrees of severity: very low (0.0 to 1.1$)$, low (1.2 to 2.6), moderate (2.7 to 4.4 ), high ( 4.5 to 6.5 ) and very high (6.6 and more). High values indicate poor oral health conditions in the population, often associated with unfavorable socio-economic conditions, difficult access to services and harmful habits, such as high sugar consumption. It can also indicate limited access to fluorine. ${ }^{6}$

Research with animals and humans show that xylitol can be used as a food ingredient, having several clinical applications, indicated as a noncariogenic biostatic sweetener, substituting sucrose in foods, including chewing gums to prevent caries. The consumption of xylitol has been recommended in some countries for several years as an additional procedure for reducing tooth decay. Thus, the aim of this work is to carry out a literature review on the use/administration of xylitol in the prevention of caries and its incorporation in diet as a sweetener.

\section{ETIOLOGY OF CARIES}

Dental caries is a chronic and multifactorial disease, caused by organic acids derived from the fermentation of dietary carbohydrates (sugar dependent) and by bacteria. When associated with a limited ability of oral $\mathrm{pH}$ correction, it may lead to tooth decalcification, in a process known as demineralization. ${ }^{7,8}$

The accumulation of bacteria on the teeth and the frequent ingestion of sugars are factors responsible for the caries development, because every time the sugar is ingested it penetrates the dental plaque where it is converted into acid, causing drop in salivary $\mathrm{pH}$. Below the critical 
$\mathrm{pH}$ level (which also depends on salivary phosphate and calcium levels), enamel hydroxyapatite will start to dissolve, releasing phosphate, calcium and hydroxil ions. ${ }^{9,10}$

Streptococcus mutans (SM) are Gram-positive cocci, a-hemolytics, catalase negative, facultative anaerobes, acidogenic and aciduric, capable of forming extracellular polysaccharides resulting from the use of hydrolysis energy, primarily from sucrose in cariogenic diets that facilitates bacterial adhesion to dental structures and other microorganisms. They are cariogenic markers related to the bacterial biofilm involved in the appearance and progression of caries, being able to metabolize / ferment different types of carbohydrates into acids, mainly sucrose, demineralizing tooth enamel. ${ }^{11-14}$

In these conditions, the metabolic pathways of SM favor the reduction of $\mathrm{pH}$, demineralization of the dental substrate, the synthesis of extracellular polysaccharides that act as an energy reserve and adhesive strategy. ${ }^{15-17}$

Streptococcus sobrinus and / or Lactobacillus spp. are other colonizing and cariogenic species, but depending on their connection to dental plaque. These micro-organisms have an affinity for salivary glycoproteins secreted over smooth dental surfaces, on the other hand, SM resides in grooves and small fissures, where it produces dextran, a strongly adherent polysaccharide, which is used for its attachment to dental surfaces. ${ }^{18-20}$

The dental biofilm presence on the surface of teeth, characterizes the initial phase of the cariogenic process in the same way that frequent exposure to sugars in the diet causes an imbalance between deremineralization, especially when salivary $\mathrm{pH}$ is lower. ${ }^{5}$

Individual salivary and behavioral factors, such as dietary habits and self-care, especially the flouretized toothpaste use, can modulate this process, in which saliva is able to remove cariogenic substrates due to the presence of bicarbonate and phosphate ions that neutralize acids produced by bacteria. ${ }^{21,22}$

Saliva is important because it helps, in a natural way, doing a self-cleaning and working as a natural defense, regulating oral $\mathrm{pH}$, in addition to ensuring the processes of remineralization of teeth, as well as in the capture of lost ions. ${ }^{21}$

In this context, the interaction of these factors for a certain period of time, favors the disease development that begins with the appearance of an opaque white spot, without cavitation, on the tooth surface, resulting from the tooth enamel demineralization. Therefore, if the evolution of the disease is not interrupted, several teeth may be affected, causing serious local, systemic, psychological and social repercussions. ${ }^{17,23}$

However, the consumption of foods rich in sugar, both sugary liquids, as well as foods that promote greater adhesion to the dental surface favors the caries development. The components of a diet rich in sugars can favor a thick biofilm formation and this when not removed, is capable of performing dental demineralization, due to the low $\mathrm{pH}$ that makes it difficult to demineralize at the biofilm tooth interface. ${ }^{2,24}$

Thus, the oral health of children bottle-feeded with sweetened formulas during the night suffers the side effects of such practice, characterizing a situation highly conducive to the development of cariogenic lesions. The greater consumption of certain foods containing sugars throughout life allied to the habit of not periodically attending the dentist, the higher the prevalence of dental caries in adolescence..$^{22,25}$

\section{CARIES DISEASE PREVENTION AND TREATMENT}

The best strategies to prevent caries are based on minimal sucrose intake, brushing teeth with fluoride toothpaste, use of dental floss and prophylaxis performed by the dental surgeon to remove plaque, in addition to the use of fluoride. Professional plaque and tartar removal at regular intervals of time slows down the progression of periodontal disease. $^{2,20}$

As the first tooth erupts, the cleaning should be carried out for three minutes, using a soft brush or gauze. The purpose of brushing and flossing is to eliminate and/or disorganize the plaque that forms on teeth surface. Thus, the correct hygienization must be carried out, after each meal, preferably in the next thirty minutes, the period of time necessary for the germs to begin to elaborate acid secretions. ${ }^{2,26,27}$

Water fluoridation is an excellent selective means of preventing caries and can be considered an effective, low-cost and far-reaching method for the entire population. The initial concentration of soluble ionic or ionizable fluoride in dentifrices must be a minimum of 1,000 parts per million (ppm) and a maximum of 1,500 ppm and the fluoride must be reactive in both tooth enamel and dentin. Therefore, fluoride treatment has proven to be important in reducing the prevalence and severity of caries, mainly associated with the use of fluoridated toothpaste in addition to a controlled and/or balanced diet that improves quality of life and oral health. ${ }^{27-29}$

More current concepts characterize dental caries as multifactorial chronic dysbiosis, sugar dependent, which involves variables such as: cariogenic diet, poor oral hygiene habits, oral microbiome and socioeconomic factors related to the individual. $2,26,30$

\section{XYLITOLCHEMICAL COMPOSITION AND DEFINITION}

Xylitol is a polyalcohol (polyol), that is, an alcohol attached to each carbon atom of its molecule, a hydroxyl group (Figure 1) with molecular formula $\mathrm{C}_{5} \mathrm{H}_{12} \mathrm{O}_{5}$. It can be found in lichens, fungi, algae and vegetables and it is also an intermediary in the metabolism of carbohydrates in Humans. In addition, is a sweetener perfectly capable of replacing sucrose, it is tolerated by diabetics and has several clinical applications inducing dental remineralization. ${ }^{31-33}$

Xylitol is an alcoholic sugar that hardly undergoes fermentation by oral bacteria. Therefore, it has been recommended as a sugar substitute, especially when food is eaten between meals, as they have properties that help prevent tooth decay. ${ }^{34}$

The refreshing effect of xylitol when in contact with saliva, occurs due to its organoleptic characteristics that enhance the refreshing effect of mint flavored products, such as chewing gums. ${ }^{31,35}$

Because it has a pleasant taste similar to sucrose, xylitol can replace it without losing organoleptic characteristics and can contribute to longterm weight control, since the caloric value of xylitol is approximately 2.4 $\mathrm{kcal} / \mathrm{g}$, while the gram of sucrose approximately $3.87 / \mathrm{g} \mathrm{kcal}$. In addition, xylitol has a low glycemic index of $7 \pm 7$ compared to a value of 100 for glucose, without altering serum insulin responses and can be considered a component for adapting diets in diabetic patients. ${ }^{36,37}$

Xylitol is not digested by human enzymes and approximately $50 \%$ of the consumed amount is absorbed by passive diffusion in the small intestine

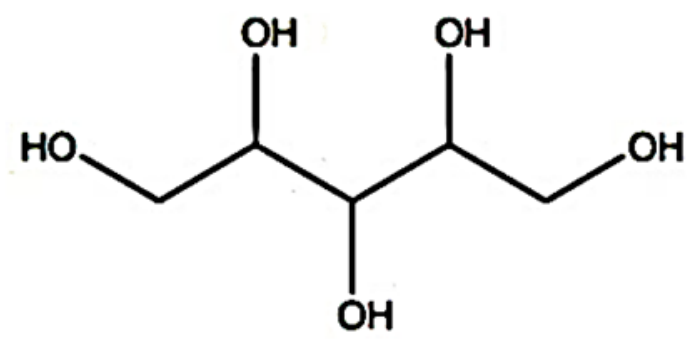

Figure 1: Chemical formula flat structure of xylitol. 
and the remaining $50 \%$ enters the colon, serving as a source of energy and carbon for the intestinal micro biota, which leads to the formation of short chain fatty acids that provide immune system homeostasis. Such properties of xylitol are very similar to those of prebiotics, where a substrate is used selectively by host micro-organisms conferring health benefits. $^{38,39}$

The increased concentration of xylitol in the digesta leads to the osmotic pressure increasement, which contributes to the water retention in the digesta and, therefore, can lead to laxative effects when consumed in excess $(>20 \mathrm{~g})$. However, this property of xylitol can also be used to treat constipation, which is in line with this prebiotic characteristic. ${ }^{38}$

Xylitol has activities that go beyond oral health. Food exposure can improve skin thickness, serving as a barrier to dermal pathogens and stimulating immunity against infectious agents. ${ }^{40}$

The oral health benefits of xylitol are well established and proven in several studies, encouraging the use of this substance in oral antiseptics, tooth creams, lozenges and chewing gums that have an action to fight against cavities. ${ }^{41,42}$

The use of xylitol in different formulations, mainly in lozenges and chewing gums, intensifies the saliva buffer capacity by increasing the salivary flow, thus decreasing the accumulation of biofilm, maintaining $\mathrm{pH}$ levels and, consequently, neutralizing the deleterious effects of acids produced by the presence of fermentable carbohydrates in the diet. ${ }^{42,43}$

Studies indicate that xylitol can act through three mechanisms: replacing cariogenic sucrose, stimulating salivation and specific inhibitory effects against MS, which is the main micro-organism that causes tooth decay. ${ }^{40,44}$

\section{ANTIMICROBIAL ACTION}

Xylitol is a kiostatic sweetener, not cariogenic like other polyols, that is, bacteria located in the oral cavity will not be able to metabolize (ferment) and produce acids, inhibiting the development of new cavities. ${ }^{2,33}$

The antimicrobial activity of xylitol occurs when the compound is incorporated into the bacterial cell, through the phosphorylation process in the glycolytic pathway of the bacterium, forming xylitol-5phosphate that is not metabolized by any enzyme, characterizing it as an intermediate compound. As there is no formation of acids and no gain of ATPs (Adenosine triphosphate), xylitol-5-phosphate becomes toxic to the bacterial cell, pushing it out of its cytoplasm. When this compound is transported into the cell and later released in the form of xylitol-5phosphate, the bacterial cell loses a lot of energy during the process, causing wear and even cell death. ${ }^{33}$

Given the assumption, with the reduction of insoluble polysaccharides and consequently of SM, oral hygiene becomes easier when associated with mechanical brushing processes with floured toothpaste. ${ }^{45}$

One of the most relevant properties of xylitol is determined by the fact that it is a non-fermentable sugar from bacteria of the genus Streptococcus, mainly SM, in addition it also acts in the remineralization process, preventing the $\mathrm{pH}$ drop of the dental surface due to its inhibitory power of growth of cariogenic bacteria (Figure 2). In this context, the use of this substance for oral washing increases the salivary flow and consequently increases the $\mathrm{pH}$ of the plaque, neutralizing possible acids that are produced by fermentable sugars. ${ }^{30,31}$

Therefore, oral health must be maintained mainly by good hygiene (mainly regular use of fluoride toothpaste), as well as by reducing the intake of sugars or even by the use of non-cariogenic sweeteners, because the sooner and the greater the quantity than the colonies appear on teeth, the greater the risk of developing cavities. ${ }^{31,46}$

The selective antimicrobial activity of xylitol, observed in oral health, was also applied to the treatment of wounds. In vitro studies with a Lubbock

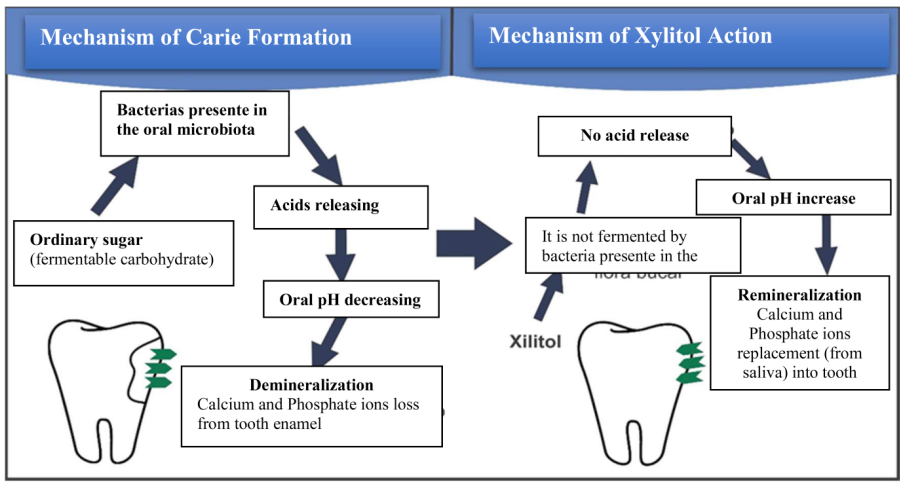

Figure 2: Process of remineralization of teeth due to the consumption of xylitol.

chronic wound biofilm model showed that application of xylitol at $2 \%$, $10 \%$ and $20 \%$ in water reduced the growth of Pseudomonas aeruginosa, Staphylococcus aureus and Enterococcus faecalis compared to water control. 46 The highest concentration was observed for preventing the formation of biofilm. In addition, another in vitro study showed that the combination of 5\% xylitol and 2\% lactoferrin could reduce the biofilm formation of $P$. aeruginosa and Methicillin-resistant S. aureus (MRSA). ${ }^{47}$ Xylitol has several antimicrobial advantages related to oral health, reducing the growth of SM and Lactobacillus spp. in saliva, in addition to stabilizing the calcium and phosphate ions that will help in the remineralization process of teeth in the prevention of already formed cavities. Furthermore, xylitol has the ability of stimulate salivation, without increasing the concentration of acids in the dental plaque, controlling the $\mathrm{pH}$ of the environment and the buffering capacity of saliva after the comsumption of sucrose..$^{30,45}$

\section{CONCLUSION}

It is noteworthy that the daily use of chewing gum containing xylitol in its formulation can modify the evolutionary process of the disease by increasing the salivary flow and, in the long run, preventing the appearance of carious lesions. However, the use of xylitol alone does not exclude the mechanical or chemical means of dental biofilm controlling.

Since 1970, numerous studies have analyzed the xylitol influence in the dental caries prevention, in the control of risk factors for carries, including MS infection and in the maternal transmission of this microorganism. It is a safe nutrient for human use / consumption. However, studies are still needed to evaluate the effectiveness of xylitol under ideal conditions conducive to its use, such as randomized clinical trials to examine its clinical efficacy.

\section{CONFLICT OF INTEREST}

The authors declare no conflict of interest.

\section{REFERENCES}

1. Valadas LAR, Gurgel MF, Mororó JM, DaCruz F, Fonteles SG, DeCarvalho CSR, et al. Dose-response evaluation of a copaiba-containing varnish against Streptococcus mutans in vivo. Saudi Pharmaceutical Journal. 2020;27(3):363-7.

2. Neto EMR, Valadas LAR, Lobo PLD, Fernandes AMB, DaCruz FSG, Fechine $\mathrm{FV}$, et al. Dose-response evaluation of propolis dental varnish in children: A randomized study. Recent Pat Biotechnol. 2020;14(1):41-8.

3. Silveira MF. Tooth decay and associated factors among adolescents in the north of the State of Minas Gerais, Brazil: A hierarchical analysis. Ciência and Saúde Coletiva. 2015;20(11):3351-64.

4. Tommasi MHM. Diagnóstico em patologia bucal. 4.ed., São Paulo: Elsevier. 2014. 
5. Lopes LM, et al. Indicators and risk factors of dental caries in children in Brazil: A literature review. RFO UPF. 2014;(19)2:245-51.

6. Brasil. Ministério da Saúde. Secretaria de Atenção à Saúde. Secretaria de Vigilância em Saúde. SB Brasil 2010: Pesquisa nacional de saúde bucal: resultados principais Brasília: Ministério da Saúde. 2012

7. Werneck RI, Mira MT, Trevilatto PC. A critical review: An overview of genetic influence on dental caries. Oral Diseases. 2010;16:613-23.

8. Furtado JJHC, Valadas LAR, Fonseca SGDC, et al. Clinical and Microbiologica Evaluation of Brazilian Red Propolis Containing-Dentifrice in Orthodontic Patients: A Randomized Clinical Trial. Evid Based Complement Alternat Med. 2020:2020:8532701. doi:10.1155/2020/8532701

9. Silva MDA, Valadas LAR, Júnior FJG, DeOliveira GAL, DeMello FAC, Neto EMR, et al. Perception and Adverse Effects of Patients after using Propolis-Containing Dentifrice. Journal of Young Pharmacists. 2019;11(4):421.

10. Cury J. Cariologia: Implicações e aplicações clínicas. In: Odontologia restauradora: Fundamentos e possibilidades. $2^{a}$ ed. São Paulo: Santos. 2002

11. Neves MVM, Silva TMS, Lima EO, Cunha EV, Oliveira EJ. Isoflavone formononetin from red propolis acts as a fungicide against Candida sp. Braz J Microbiol. 2016;47(1):159-66.

12. Tanner AC, et al. Cultivable anaerobic microbiota of severe early childhood caries. J Clin Microbiol. 2011;49(4):1464-74.

13. Moye ZD, Zeng L, Burne RA. Fueling the caries process: carbohydrate metabolism and gene regulation by Streptococcus mutans. J Oral Microbiol. 2014;6:24878

14. Yang $Y$, Sreenivasan PK, Subramanyam $R$, Cummins D. Multiparamete assessments to determine the effects of sugars and antimicrobials on a polymicrobial oral biofilm. Appl Environ Microbiol. 2006;72(8):6734-42.

15. Bowen WH, Burne RA, Wu H, Koo H. Oral Biofilms: Pathogens, Matrix and Polymicrobial Interactions in Microenvironments. Trends Microbiol. 2017; S0966842X(17)30213-5.

16. Holbrook WP, Magnúsdóttir MO. Studies on strains of Streptococcus mutans isolated from caries-active and caries-free individuals in Iceland. Journal of Ora Microbiology. 2012:4:106-111.

17. Martins $\mathrm{ML}$, et al. Efficacy of red propolis hydro-alcoholic extract in controlling Streptococcus mutans biofilm build-up and dental enamel demineralization. Archives of Oral Biology. 2018;93:56-65

18. Madigan MT, et al. Microbiologia de Brock. 14. ed. Porto Alegre: Art Med. 2016

19. Barbieri DS, Tonial F, Lopez PV, Maia BHS, Santos GD, Ribas MO, et al. Antiadherent activity of Schinus terebinthifolius and Croton urucurana extracts on in vitro biofilm formation of Candida albicans and Streptococcus mutans. Archives of Oral Biology. 2014;59(9):887-96.

20. Tortora GJ, Funke BR, Case CL. Microbiologia. 12. ed. Porto Alegre: Artmed. 2017.

21. Kawakita ERH, et al. Effect of Chitosan Dispersion and Microparticles on Older Streptococcus mutans Biofilms. Molecules. 2019;24(9):1808.

22. Feldens CA, et al. Cárie Dentária na infância: Conceitos Preliminares. Cárie Dentária na Infância: uma abordagem contemporânea. São Paulo: Santos. 2013.

23. Losso EM, et al. Cárie precoce e severa na infância: Uma abordagem integral. J Pediatr. 2009;85(4):295-300

24. Dini EL, Holt RD, Bedi R. Caries and its association with infant feeding and oral health-related behaviours in 3-4-year-old Brazilian children. Community Dent Oral Epidemiol. 2000;28(4):241-8.

25. Brito AS, et al. Sociodemographic and behavioral factors associated with dental caries in preschool children: Analysis using a decision tree. $\mathrm{J}$ Indian Soc PedoPrev Dent. 2018;36(3):244-9.
26. Tenuta LM, Cury JA. Fluoride: its role in dentistry. Braz Oral Res. 2010;24(Suppl):9-17.

27. Areias $C$, et al. Cáries precoces da infância: $O$ estado da arte. Acta Pediátrica Portuguesa. 2010;41(5):217-21.

28. Mendonça ICG, et al. Monitoring the activity of initial injuries of caries in students in a school in the municipality of Maceió-AL after conservatory preventive treatment. REAS/EJCH. 2019;20(e584):1-10.

29. Moura MS, Moura LFAD, Mendes RF. Dental caries in children under five years old in Teresina-PI. Rev Odontol UNESP. 2010;39(3):143-9.

30. Simon-Soro A, Mira A. Solving the etiology of dental caries. Trends in microbiology. Trends in Microbiology. 2015;23(2):76-82.

31. Mussatto SI, Roberto IC. Xilitol: Edulcorante com efeitos benéficos para a saúde humana. Brazilian Journal of Pharmaceutical Sciences. 2002;4(38):401-13.

32. Xavier LAC, et al. Analysis of genome instability biomarkers in children with non-syndromic orofacial clefts. Mutagenesis. 2017;32(2):313-21.

33. Rédua RB, Lorenzoni $B$, Filho AV, Laurente RL. Existe justificativa para o uso do xilitol na prevenção da cárie? Uma revisão de literatura. Full Dent Sci. 2019;10(40):128-34.

34. Calderón J, et al. Efectividad de los polialcoholes en la prevención de la caries dental: Una revisión sistemática. Rev Venez Invest Odont IADR. 2019;7(2):6-35.

35. Alamoudi NM, et al. Impact of maternal xylitol consumption on mutans streptococci, plaque and caries levels in children. J Clin Pediatr Dent 2012;37(2):163-6.

36. Bond M, Dunning NX. Sweeteners and sugar alternatives in food technology Blackwell; Oxford,UK. 2006;295-324.

37. Oliveira GGC, et al. Antibacterial and anticariogenic properties of xylitol a literature review. Rev Bras Odontol. 2018;75:e960.

38. Gibson GR, et al. Expert consensus document: The International Scientific Association for Probiotics and Prebiotics (ISAPP) consensus statement on the definition and scope of prebiotics. Nature Reviews Gastroenterology and Hepatology. 2017;14(8):491-502.

39. Lenhart A, Chey WDA. Systematic Review of the Effects of Polyols On Gastrointestinal Health and Irritable Bowel Syndrome. Advanced Nutrition. 2017;(8)494:587-96

40. Salli K, Lehtinen MJ, Tiihonen K, Ouwehand AC. Xylitol's Health Benefits beyond Dental Health: A Comprehensive Review. Nutrients. 2019;11(8):1813.

41. Nayak PA, Nayak, UA, Khandelwal V. The effect of xylitol on dental caries and oral flora. Clinical, Cosmetic and Investigational Dentistry. 2014;6:89-94.

42. Janakiram C, Deepan KCV, Joseph J. Xylitol in preventing dental caries: A systematic review and meta-analyses. J Nat Sci Biol Med. 2017;8(1):16-21.

43. Montanuci LMGM, et al. Efeito de Diferentes Gomas de Mascar sobre o $\mathrm{pH}$ Salivar de Crianças. Pesquisa Brasileira Odontoped Clinica Integrada. 2013;13(1):23-9

44. Ly KA, Riedy CA, Milgrom P, Rothen M, Roberts MC, Zhou L. Xylitol gummy bea snacks: A school-based randomized clinical trial. BMC Oral Health. 2008;8:20.

45. Escalante-Medina RP, Asmat-Abanto AS, Ruiz-Barrueto MA. Efecto de una Pasta Dental Comercial Conteniendo Xilitol Sobre el Recuento de Streptococcus mutans en Saliva de Gestantes: Ensayo Clínico Controlado Aleatorizado. International Journal of Odontostomatology. 2019;13(3):316-20.

46. Dowd SE, et al. Effects of biofilm treatments on the multi-species Lubbock chronic wound biofilm model. J Wound Care. 2009;18(12):508, 510-12.

47. Nurunnabi TR, et al. Anti-MRSA activity of oxysporone and xylitol from the endophytic fungus Pestalotia sp. growing on the Sundarbans mangrove plant Heritiera fomes. Phytotherapy Research. 2018;32(2):348-54.

Article History: Submission Date : 11-05-2020; Revised Date : 21-06-2020; Acceptance Date : 16-07-2020

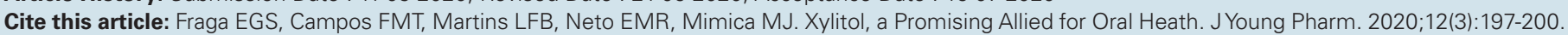

